Este artigo analisa a complicada relação entre educação e psicanálise com base no primeiro es tudo de caso de Melanie Klein, sobre "Fritz", o estudo de Freud do "Pequeno Hans" e um filme contemporâneo. Todos eles representam dilemas da relação criança-adulto, e o fazem através de surpreendentes questionamentos por parte das crianças sobre a sexualidade $\mathrm{e}$ a natureza da existência. Esses textos do arquivo introduzem também a questão de 'o que mais a educação pode significar quando se levam em conta a associação livre e o inconsciente?' Finalmente, 0 artigo reflete sobre o dificil conbecimento colocado pelo problema de se conhecer a história de alguém por meio da questão do Outro.

Psicanálise com crianças; Melanic Klein; sexualidade; cducação; dificil conhecimento

THE RETURN OF "THE QUESTION CHILD": READING MA VIE EN ROSE THROUGH MELANIE KLEIN

This paper analyzes the uncasy relationship between education and psychoanalysis by way of Melanie Klein's first case study of "Fritz,", Freud's study of "Little Hans" and a contemporary film. They all represent dilemmas in child/adult relations but do so through the child's startling questions about sexuality and the nature of existence. These archival texts also open a question of what else education can mean when free association and the unconscious are respected. Finally, the paper considers the difficult knowledge made from the problem of knowing one's history through the question of the Other. Child psychoanalysis, Melanie Klein; sexuality; education, difficult knowledge

\section{O RETORNO DA "CRIANÇA- QUESTÃO”: UMA LEITURA DO FILME MA VIE EN ROSE A PARTIR DE MELANIE KLEIN ${ }^{1}$}

\author{
Deborah P. Britzman \\ Tradução: Luciana Pérez de Campos Pires
}

\section{O ARQUIVO}<smiles>[C]1=[C-]C=C1</smiles>

ez por outra, uma figura curiosa escapa do arquivo psicanalítico ${ }^{2}$. Pontalis $(1981$, p.95) chama essa figura sinistra (Unheimlich) de "a criançaquestão”. Ele produz essa metáfora a partir da leitura do primeiro e estranhíssimo relato de Melanie Klein (1921) da análise de seu filho de cinco anos, no qual ela leva a cabo o que era chamado na época de uma "educação psicanalítica". Antes de adentrar na essência dessa metáfora, vale, contudo,

Professora de Educação e diretora do programa de pós-graduação em Pensamento Político e Social da York University no Canadá. 
tecer um breve comentário sobre o lugar que esse artigo ocupa na história do arquivo psicanalítico, sobretudo o que ele inaugura para a prática psicanalítica e sua teoria, e para a educação. Existem, é preciso lembrar, outras crianças-questão, talvez a mais famosa delas - a primeira - foi o decepcionante estudo de caso de Freud (1909) do "Pequeno Hans" 3 . No entanto, Klein levou essa metáfora a surpreendentes proporções; seu relato afetou o arquivo psicanalítico de uma forma que o Pequeno Hans não pôde - mesmo tendo feito as mesmas perguntas a seus pais. Enquanto o Pequeno Hans parecia justificar o uso da teoria psicanalítica, particularmente na estranha história da ação tardia da angústia infantil, o estudo de caso de Klein, por sua vez, abriu novas, e profundamente contestadas, visões para a teoria psicanalítica.

Atualmente, o texto de Klein O Desenvolvimento de uma Criança apresenta-se como uma leitura estranha. Sua escrita é difícil de ser acompanhada e se prolonga em frases sem propósito. O texto é, na realidade, composto de dois diferentes escritos, com dois anos de intervalo entre eles. A primeira parte, escrita em 1919, foi seu trabalho de qualificação para admissão na Sociedade de Psicanálise de Budapeste. Esse trabalho representa a primeiríssima tentativa de Klein de relatar a análise de uma criança, e talvez de proferir outra justificativa à relevância do processo para a própria criança. Nesse texto, sua crença na educação psicanalítica e em seu objetivo de esclarecimento sexual é inabalável. Na parte 2 do artigo, entretanto, escrita alguns anos depois, Klein descarta essa crença e contesta sua insistência anterior na utilidade da psicanálise profilática. A crença na educação e, conseqüentemente, no esclarecimento - Aufklärung - do qual a educação era tida como representante torna-se ambivalente.

Olhado de forma retrospectiva, esse relato também inicia uma guerra de artigos nas eternas discussões que a autora trava com Anna Freud ${ }^{4}$. Ao longo de suas vidas, Melanie Klein e Anna Freud discordariam sobre como interpretar a luta entre realidade e fantasia na análise infantil. Anna Freud (1928) achava que se a fantasia era o tópico do diálogo psicanalítico, a analista devia, com o intuito de educar, aproximar a criança da tarefa do teste de realidade. No começo, Klein concordou. Mas, em 1923, teve profundas dúvidas sobre o que o analista devia interpretar. Ao longo de suas longas carreiras, essas fundadoras da análise de crianças discutiram sobre o lugar da educação no diálogo psicanalítico com crianças. Quando $O$ Desenvolvimento de uma Criança foi reeditado, nas obras completas de Klein (1975), continha uma nota de rodapé, acrescentada em 1947, que negava com maior veemência seu primevo otimismo no papel da educação na psicanálise. Nessa nota, 
a autora caracteriza sua antiga crença como algo "necessariamente ligado ao seu conhecimento psicanalítico da época”. Ela parece sugerir que o arquivo não envelhece bem e que, em nosso retorno a ele, devemos interpretar o status de seu conhecimento, outrora e agora. O artigo causa estranhamento também porque Klein analisa seu próprio filho - uma prática aceitável naquele tempo -, embora esse fato seja disfarçado em sua sinopse do estudo de caso. Seu filho Erich transforma-se no garoto "Fritz" do artigo e Klein passa então a se referir a si mesma na terceira pessoa. Mesmo Klein descrevendo esse seu primeiro trabalho como "educação com feições analíticas”, podemos dizer, em retrospectiva, que esse artigo também representa o início da técnica psicanalítica do brincar de Klein, na qual interpretar as fantasias e angústias das crianças tem precedência em relação a quaisquer tentativas educativas. Aliás, nesse primevo estudo de caso, podemos vislumbrar o início do esforço de Klein para escutar analiticamente, para interpretar não as questões literais que eram formuladas pelas crianças, mas aquelas que eram deixadas sem formulação. Dessa forma, a metáfora da "criançaquestão" torna-se rica em possibilidades, imprimindo à fantasia inconsciente profundidade e surpreendente força e insistência.

Assim, Klein começa uma educação psicanalítica com seu filho, com a idéia de esclarecê-lo sobre o que ela chamava de "questões de ordem sexual”. Ao responder quaisquer de suas questões com honestidade, Klein pensava ajudá-lo a prevenir que ele tivesse um futuro de tendências neuróticas, além de, uma vez por todas, liberar a sexualidade de sua aura de mistério e de grande parte de seu perigo (1-2). Mas seu filho já havia sinalizado seu descontentamento; nele, estava já posta, na visão de Klein, uma certa inibição da curiosidade. Originalmente, Klein interpretou o apego de Fritz à superstição, à figura fantasiosa do "Coelhinho da Páscoa”, e, dessa forma, à fé absoluta de que seus desejos seriam atendidos, como se ele tivesse parado de pensar. De fato, Fritz não queria que seus desejos e teorias fossem testados pelo conhecimento do adulto: ele não queria ser esclarecido. Mas ele também não queria esperar a experiência tornar-se história.

As coisas se tornam um tanto absurdas. A um certo ponto, o garoto de cinco anos, Fritz, acredita que é um cozinheiro gourmet, que fala francês fluentemente e pode consertar quaisquer objetos que tenham se quebrado. Enquanto Klein explica pacientemente que ele não pode fazer nenhuma dessas coisas - que ele precisa aprender -, Fritz responde calmamente: "Se me mostrarem como se faz uma vezinha só, eu posso fazer isso muito bem!" Ele se agarra firmemente a esse belo refrão; é sua última palavra. Algo sobre ter que aprender é omitido e Klein coloca o que está sendo deixado de lado sob o título assombroso de "A resistência da criança ao esclarecimento". É possível, eu acho, perguntar a que exatamente está resistindo, já que outras partes desse primeiro artigo colocam a luta de Fritz sob o grande tema da existência. Ou seja, Fritz se 
pergunta sobre a natureza da realidade e seus julgamentos, a qualidade do tempo, da história, e da memória, a definição de seus direitos e poderes, o futuro de seus desejos e esperanças, o significado do nascimento e da morte, e se Deus existe.

Esses são problemas delicados que nos levam ao domínio sonhador da tentativa de simbolização de nosso encontro tanto com a realidade quanto com a fantasia. E se Fritz agora está se parecendo um pouco com o filósofo Kant, tentando conhecer as coisas-em-si-mesmas e a toda hora se chocando contra sua própria subjetividade; essas questões forçam Klein a chegar mais próximo do que nunca de seus próprios desejos por esclarecimento. E é a partir dessa confrontação que emerge a figura da criança-questão. Será que Fritz estaria interessado em tentar distinguir entre suas fantasias e sua realidade? $O$ que pode o conhecimento significar nessa divisão? Por que ele se agarrou tão firmemente a suas explicações sobre como o mundo deveria funcionar? Talvez Fritz estivesse desconstruindo as duas esferas e isso o estava detendo. Embora Klein comece a pensar sobre onipotência infantil - um modo de pensamento teimoso, que mesmo enterrado por ter de crescer, é ainda preservado através de nossos desejos por aprendizado e existencia -, ela está também no percurso de sua própria educação como analista, e quiçá como mãe. Estranho, então, um estudo de caso, que a refreie quanto a educar seu filho, retome sua confrontação com sua própria educação: não o esclarecimento, mas a natureza (inconsciente) da existência enquanto tal.

Suponhamos que o ponto de vista inicial de Klein, ao qual ela primeiro chamou de "educação psicanalítica”, não esteja além de nosso próprio arquivo, a pedagogia contemporânea centrada na criança. Lá, a curiosidade da criança determina o currículo, o professor profere conhecimento para o uso da criança, o conhecimento é a descoberta de como as coisas funcionam e a intervenção do adulto segue os passos das preocupações das crianças e, dessa forma, auxilia em sua alteração. Não é o caso de dizermos que esses objetivos educacionais não valham a pena; embora eles sejam facilmente desviados por tudo que exceda o literal, em outras palavras, nossa resistência para tudo mais que a curiosidade sinaliza. Quando essa orientação sobre como o conhecimento se faz organiza a educação psicanalítica, os esforços do adulto em guiar a criança excluem a percepção do trabalho do inconsciente. De onde vem a curiosidade de alguém e o que a interrompe precocemente? Se alguma coisa estranha aconteceu a Klein no seu caminho em direção à sua educação - se, brevemente falando, ela encontrou "uma criança-questão" -, algo difícil também acontece com a educação.

Klein tinha dificuldade em conceber a natureza da curiosidade - de onde ela vem, o que representa, como ela se desprende de seu objeto e, assim, o que significa apressar essa facilidade. Essas questões também avivaram algo novo sobre sua própria curiosidade; Klein descobriu, com a 
resistência da criança ao esclarecimento, sua própria resistência ao que mais a criança perguntava. Nós estamos entrando no domínio psicanalítico da transferência: a troca de desejos inconscientes, o deslocamento de nosso primeiro amor para figuras de autoridade, a transposição de equivalências simbólicas de conflitos antigos e reprimidos para a compreensão de novas situações. Significantemente, Freud (1912) escreve sobre transferência como uma dinâmica, uma relação, e associa sua indelével assinatura à permissão de investigação. Ao tentar saber algo novo, nosso arquivo psíquico é aberto. A transferência, escreve Freud, nasce do "compromisso entre as demandas da [resistência] e as do trabalho de investigação" (Freud, 1912, p.103). Alguma coisa dentro do próprio trabalho de investigação resiste e instiga suas próprias demandas. E, em psicanálise, essa resistência pode simbolizar um paradoxo: há mistério na sexualidade e o conhecimento não pode retirá-lo. Mas há também mistério no conhecimento porque nós temos sexualidade. É nesse ponto que nossa educação ilusória fracassa e naufraga.

Ao ler esse primeiro estudo, pode-se ficar impactado com a qualidade insolúvel das questões de Fritz e talvez perguntar qual tipo de trabalho essas questões tentavam realizar. De certa forma, as exaltadas respostas de Klein a seu filho parecem indicar que ela também foi capturada por esse mistério. Fritz pergunta: "Como os olhos ficam dentro? Como uma pessoa ganha a sua pele?". Ocorre então uma outra questão: "Quando serei mamãe?"5. No entanto, mesmo se Klein tentasse respondê-las (e, em breve, veremos as estranhas discussões que suas tentativas produziram), seu filho se recusava a acreditar nela. E Klein passou a acreditar que a prova preferida não era critério para o estabelecimento de uma realidade convincente. A realidade teria que passar pela resistência e pela investigação. As questões dessa criança desafiavam tanto a imaginação dos adultos quanto as noções convencionais de tempo. Afinal de contas, como você poderia responder à preocupação: onde eu estava antes de nascer? Ou ainda, quando o garoto se tornará uma mamãe? Cada questão assemelha-se ao negativo de uma fotografia. As qualidades particulares das perguntas que ele tentava formular como, por exemplo, como me mantenho inteiro? o que acontecerá comigo por que eu sou eu? e em que sou parecido com você? podem ser suavemente agrupadas sob o signo da existência enquanto tal. A questão inconsciente pode ser: o que posso fazer porque fui feito? Até que essa série, ao mesmo tempo estranha e familiar, de preocupações pudesse ser testemunhada, tanto Klein quanto seu filho estavam capturados pelo resplendor do Esclarecimento. Quanto mais a criança perguntava, e mais a mãe respondia, mais ansio- 
so, repetitivo e estereotipado tornava-se o discurso deles. A própria educação psicanalítica, que implicava expandir a curiosidade, tornou-se para mãe e filho algo como uma inibição intelectual.

Observe-se a conversa entre Melanie Klein e seu filho no tópico de como são feitos os bebês. Klein ofereceu essas explicações na linguagem da criança como uma forma de ajudar seu filho a desistir de sua teoria de que os bebês são feitos de leite. Contudo, a linguagem da criança é bastante engenhosa na medida em que pode sustentar suas primeiras teorias. Afinal de contas, leite tem, de fato, algo a ver com isso tudo.

"Quando começo a falar novamente do ovinho, ele interrompe: 'Eu sei disso.' Eu continuo: 'O papai faz uma coisa com o pipi dele que realmente parece com leite e que se chama semente; ele faz isso como se estivesse fazendo pipi, mas só que um pouco diferente. O pipi da mamãe é diferente do do papai' (ele me interrompe) 'Eu sei disso!' Eu explico: 'O pipi é que nem um buraco. Se o papai bota o pipi dele dentro do pipi da mamãe e faz a semente lá, então a semente corre mais fundo para dentro do corpo dela e quando se encontra com um dos ovinhos que estão dentro da mamãe, o ovinho começa a crescer e se transforma numa criança.' Fritz ouviu com grande interesse e disse: 'eu queria tanto ver como uma criança é feita lá dentro desse jeito.' Eu explico que isso só vai ser possível quando ele crescer, pois não pode acontecer antes, mas que então ele mesmo vai poder fazer. 'Mas então eu queria fazer isso com a mamãe'. 'Isso não pode, a mamãe não pode ser sua mulher porque ela já é mulher do papai, e aí o papai ia ficar sem mulher'. 'Mas nós dois podíamos fazer isso com ela.' Eu digo: 'Não, isso não pode. Cada homem só tem uma mulher. Quando você estiver grande, a mamãe vai estar velha.' ... 'a mamãe sempre vai amar você, mas ela não pode ser sua mulher.' ... No final, (ele) disse: 'Mas, uma vez só, eu queria ver como a criança entra e sai." 6

Há alguns graciosos momentos de déjàvu em toda essa confusão entre tempo e timing, assim como de agudeza, quando Klein percebe como essas explicações deixavam Fritz sozinho e triste. Além disso, vale notar o estranho traço de confiança de Fritz: o "Eu sei disso!" e seu desejo de ser elucidado uma vez que pudesse fazêlo por si mesmo. Essas colocações pontuam e mantêm em suspenso o pedido de sua mãe. Klein coloca essa conversa sob o título de "A resistência da criança ao esclarecimento”. A gramática da resistência se move para a frente e para trás: o conhecimento da mãe depende da aceitação por parte de seu filho do futuro perfeito. Quando Fritz se tornar adulto, ele poderá fazer essas coisas. Mas a promessa do tempo é insuficiente para a urgência do tempo presente $^{7}$ e para a ação retardada do passado perfeito da lógica da criança. Há também a paixão entre mãe e filho, um mistério de vulnerabilidade que roça as bordas da linguagem.

De fato, a vulnerabilidade de mãe e filho reside na linguagem e é levada por ela. Mesmo que o adulto use as mesmas palavras que a criança, ele 
pode estar assumindo o que Michel Balint (1992) chama de "nível edípico da linguagem", quando "as interpretações do analista são vivenciadas como interpretações pelo paciente." Fritz, vale recordar, recusa interpretação ao afirmar "Eu sei disso!". Da mesma forma faz Klein, já que suas respostas são uma tentativa de instalar, através do conhecimento, a realidade que se esquiva de Fritz. Balint está precisamente interessado no momento em que a linguagem é usada para substituir o outro. Ele sugere que, algumas vezes, a interpretação do analista não pode ser recebida pelo analisando como uma interpretação. Nesses casos, então, a linguagem do analista é percebida como se o analista estivesse castigando, alertando e perseguindo o analisando. Isso também faz parte da transferência: o conflito psíquico carregado pela linguagem é sentido antes da compreensão. O nível edípico da linguagem ocorre quando a diferença é mutuamente assumida, quando, mesmo se a linguagem não é tão adequada, ela pode gradualmente ser aceita como uma forma de construir entendimento de estados afetivos não muito facilmente acompanhados por palavras. Balint compara o nível edípico da linguagem - nossa facilidade e interesse no problema da interpretação e diferença - com o que vem antes disso: uma literalidade terrível, um colapso entre a coisa e o que tenta representála. Essa é a literalidade que Klein (1930) chamou de "equação simbólica", quando o símbolo é realidade. O problema é que há, o que Ferenczi (1933) notou, "uma confusão de línguas" entre o adulto e a criança. A linguagem do adulto não consegue apresentar-se como uma interpretação, ou como uma construção. Assim, a linguagem é recebida como se ela pudesse impor a realidade. Klein por fim entenderia que não é possível defrontar-se com a "criança-questão", se o adulto recorrer a explicações prematuras, defender-se de forma convencional, ou desejar esclarecer.

Pode-se dizer que onde há linguagem, há defesa contra a linguagem. Essa trajetória - uma questão é feita, uma resposta é oferecida, e, então, a ignorância simulada deixa nebulosa qualquer tentativa de diálogo - é próxima do modo como Freud (1900) descreveu a defesa da "Chaleira" em seu livro Interpretação dos Sonhos. Nessa passagem, um homem empresta a chaleira de seu vizinho e a devolve quebrada. "O defensor afirma primeiramente que nunca a devolveu quebrada; em uma segunda vez, a chaleira tinha um furo quando ele a emprestou, e, numa terceira vez, ele nunca havia pegado emprestada chaleira nenhuma de seu vizinho. Quanto mais melhor: se ao menos uma dessas três linhas de defesa fosse aceita como válida, o homem teria de ser absolvido"8. Veja a defesa de Fritz: sua resposta está equivocada, eu nunca perguntei sobre essa questão, eu já sabia disso. A discussão de Alice Pitt sobre o chiste da chaleira levanta um paradoxo-chave das relações educacionais: "Para que a fala funcione como uma revelação, algo acontece que é completamente novo e inesperado; a revelação transforma o ego." Se a questão for para transformar, ela deve in- 
fluenciar a própria natureza da resposta. Melanie Klein por fim entendeu que a criança-questão transforma o conhecimento do adulto, assim como seu ego e sua capacidade de reflexão. A criança-questão questiona o desejo do adulto e não há nenhum álibi para nossos desejos.

Originalmente, Klein credita muito valor ao papel da educação psicanalítica na cura da ignorância e, talvez, até mesmo dos erros da existência. Ela achou que a persuasão racional conseguiria transformar a mente de seu filho, que ela poderia dissuadi-lo de suas teorias através das palavras, e dessa forma resolver para ele os mistérios da sexualidade. Mas, ao testemunhar as questões de seu filho, ela se deu conta de uma certa repetição no conteúdo do que seu filho perguntava e no modo como ela respondia. Estamos de volta à busca do problema da existência. Fritz pergunta: "Onde eu estava antes de nascer?... Como uma pessoa é feita? ... Para que precisamos de um papai? ... Para que precisamos de uma mamãe?" Quanto mais Klein explicava, menos a criança pensava. E Klein observou: "Uma certa 'dor', uma falta de desejo para aceitar (contra o que seu desejo pela verdade lutava) foi o fator determinante de suas freqüentes repetições da questão." Onde há existência, há uma certa dor, uma ambivalência. Todas as questões de Fritz começam com o questionamento: "como eu fui feito, de onde eu vim?" Essas questões, Klein passou a suspeitar, eram também um apelo inconsciente à história ainda não formulada: "O que posso fazer a partir de como fui feito?" Escutar a questão inconsciente significava, para Klein, virar as costas para o ajuste da realidade, educadamente chamado de "esclarecimento", e colocar-se o mais próximo possível da análise das fantasias. Responder às questões de seu filho com suas próprias verdades convencionais cedeu lugar a interpretar as questões em duas linhas: na linha das defesas e na linha dos desejos inconscientes tanto do filho quanto da mãe.

Quais são então as características da criança-questão? Em primeiro lugar, as questões da criança-questão veiculam conhecimentos dificeis. Apesar de tudo indicar contrariamente, a criança-questão é capaz de pensamentos bizarros, de devolver aos adultos a resistência curiosa de sua própria linguagem edípica. A questão enerva o conhecimento do adulto, mexe com sua ansiedade e talvez seu impulso de oferecer a "defesa da chaleira". Na opinião de Adam Philip (1998), encontrar o que é inesperado requer sintonia com "algo de valor: uma atenção para a irregularidade, a excentricidade, a imprevisibilidade do que cada pessoa faz com o que recebe - a singularidade inata da história distintiva de cada pessoa". Estamos de volta à questão da existência: o que posso fazer por- 
que fui feito? "Não é uma questão de indiferença à nossa liberdade," escreve Richard Cohen em sua discussão sobre ética em nossos tempos, "o fato de que 'somos nascidos" e não causados, e por necessidade temos pais." Nossa liberdade é inexplicavelmente ligada ao outro, mesmo cada um de nós percebendo a singularidade do laço que nos liga.

Nossa criança-questão devolve ao adulto suas próprias prescrições e ansiedades, talvez devolve até mesmo seus próprios pais. Nessa troca, várias coisas podem dar certo ou errado. A criançaquestão oferece ao adulto um teste de realidade não-usual: usar a questão da criança para encontrar a verdade da existência do adulto. A criança-questão testa a realidade do adulto ao questionar o conhecimento do adulto e sua proximidade com a fantasia. Se tudo der certo, para parafrasear Pitt, a fala poderá funcionar como revelação, aliás como o começo de qualquer nova forma de interpretar o fato de existência. O que Klein percebeu como "uma certa dor", uma falta de vontade de aceitar a verdade e um desejo pela verdade ao mesmo tempo, anima o desejo. A verdade particular em jogo é, por fim, como cada um de nós passa a entender nossa singularidade imprevisível em relação à singularidade imprevisível do outro. O erro particular e necessário, e isso nos traz de volta à questão da onipotência, é que "o ego confunde a si mesmo com o eu." (Green 2000, p. 19). Se pudermos chamar esse tipo de verdade de "existência enquanto tal", deve-se, afinal de contas, fazer uma ressalva, ao mesmo tempo em que se telegrafa o que Klein chamou de "uma dor particular". Qualquer tentativa de ajustar seu significado pode parecer um pouco como a defesa da Chaleira. Sim, as coisas ficam absurdas, a linguagem perde seu objeto; ocorre o que Ferenczi testemunhou como "uma confusão de línguas". Contudo, também pode ocorrer prazer.

\section{FILME TOCANTE ${ }^{10}$}

Se no arquivo o tempo permanece parado, então vamos ao cinema. Lá, também, encontramos uma criança-questão e sua família. No filme Ma Vie en Rose (traduzido para "Minha Vida em Cor-de-rosa") aparece uma outra criança-questão que se pergunta continuamente 'qual é a natureza da minha existência para mim?' $E$, então, 'o que essa natureza tem a ver com reconhecimento e desentendimento?' A cena de abertura conta toda a história em miniatura: um garoto de sete anos, de forma cuidadosa e bela, vestiu-se como uma garota e quer que os outros o vejam. O filme 
parece interrogar a platéia sobre como vão acompanhar o desenrolar dessa história, assistindo ao desenrolar das personagens e testemunhando a história de seu próprio aprendizado se desenrolar. Qual é a natureza da educação aqui?

Nosso garoto de sete anos, Ludovic, tem uma questão urgente: "Sou um garoto ou uma garota?" Então, sua próxima questão é uma espécie de resposta: "quando me transformarei em uma garota?" Ele conta à sua mãe o que ele acredita que vai acontecer porque se apaixonou por Jerome: "Ele vai se casar comigo quando eu não for um garoto." Será que o amor transforma o ego? Mais tarde, Ludovic tenta prever o futuro através da referência ao que a história descartou; ele elabora uma teoria do sexo a partir da aula de biologia sobre cromossomo $\mathrm{X}$ e $Y$ que sua irmã lhe deu. Nesta oferta de esclarecimento, biologia é sina, não interpretação. $A$ isso sua irmã acrescenta uma autoridade: o texto da escola. A confusão de línguas provoca um estranho encontro, pois Ludovic ainda se pergunta: quais as probabilidades dos cromossomos? Será que eles são como dados lançados em direção ao caminho de uma pessoa? Ludovic brinca com essa aula quando, logo após demonstrar seu prazer ao urinar sentado no vaso sanitário, ele conta a Jerome: "Eu sou um garoto-garota. Meu X para garota caiu dentro do lixo. Foi um erro científico." Sem ter responsabilidade alguma por isso, Ludovic precisa aguardar para que seu cromossomo perdido encontre seu caminho de volta para casa. Se a natureza pode 
se perder, ele parece dizer, é apenas a ciência que está enganada.

Por um tempo, os pais de Ludovic são flagrados na defesa da chaleira. Eles, aos poucos, ficam sem ação, de tamanha preocupação: os vizinhos estão começando a falar e afastar-se da família. Os vizinhos parecem culpar os pais por não terem o controle, por permitirem as identificações de Ludovic, e por respeitálo em primeiro lugar! É apenas quando a mãe vê Ludovic vestindo sua cueca de frente para trás que ela procura uma psicóloga, juntamente com o pai e Ludovic. A psicóloga pergunta aos pais: "Vocês queriam um garoto ou uma garota?" E há um momento no consultório da psicóloga em que os pais se confrontam com sua confusão de desejo, por meio de uma pergunta não-formulada: "O que é que o desejo inconsciente dos pais significa para a criança?" O que os pais querem? Essa pergunta tem muita força e a resposta deles é uma confusão de línguas. De que maneira o desejo dos pais retorna através do que a criança ama? Em uma segunda cena, a psicóloga sugere que os pais esperem para ver e permitam que Ludovic decida se ele quer voltar ao seu consultório. Sua sugestão é sutil: retardem qualquer resposta para tornar possível a Ludovic elaborar sua questão. Deixe-o ter tempo de fazer uma história, antes que ele tenha que se preocupar em fazê-la.

A avó de Ludovic, que se recusa a envelhecer, conta à família: "Eu acho que devíamos deixá-lo viver sua fantasia." E por que não? Afinal de contas, todo mundo no filme está fazendo exatamente isso: alguns vivem sua fantasia de perseguição, outros, como as bonecas encantadoras, Pam e Bem, são mágicos e neuróticos. Escutem a canção de Pam que o pai e Ludovic cantam em altos brados: "Eu almejo ser feliz, é como uma neurose!" A família tenta seguir o conselho da avó, mas apenas como uma terapia aversiva fracassada. Eles vão a uma festa com Ludovic trajando um vestido e explicam aos vizinhos: "Nós estamos deixando ele encenar sua fantasia para que se torne banal." Mas, é claro, a banalidade reside no cruel estado de ausência de pensamento dos outros. Ludovic, afinal de contas, está sempre pensando.

Ludovic é suspenso da escola por causa de uma petição de pais e o diretor pontua: "Seu gosto é muito excêntrico para esta escola." Os vizinhos desaparecem também; o pai perde seu emprego; alguém picha na garagem da casa da família o seguinte aviso: "Vá embora garoto bicha!" e nossa criança-questão pergunta: "Por que é que os garotos bichas têm que ir embora?" A resposta de sua mãe repete a lógica da ameaça: "Bicha significa garotos que gostam de outros garotos." A mãe então corta o cabelo comprido de Ludovic. Vários outros eventos ocorrem e os pais parecem se alternar em suas descompensações. No entanto, o filme faz pouco por novas possibilidades: Ludovic e seus pais são deixados com suas questões. O futuro de Ludovic como ele vai aprender a viver, quais as estratégias que ele vai elaborar, e como os outros o acolhem - deve esperar por um outro filme, muito 


\section{Artigo}

embora nesse filme tocante o futuro mal possa esperar. Se, para vários adultos, o futuro já chegou e se faz presente através de sua ansiedade diante de Ludovic, ainda resta a admirável pergunta de Ludovic: o que fica dessa história?

\section{A QUESTÃO DA HISTÓRIA}

Qual é então o tempo da história? "No que concerne à psicanálise", escreve André Green (2000) em uma palestra sobre experiência e pensamento, "o histórico é uma noção muito difícil de tratar." A razão dessa dificuldade tem a ver com qual é a história da psique e, de um ponto de vista psicanalítico, existem realidades rivais. A definição de Green sintetiza um pouco o que Melanie Klein e, provavelmente, os adultos que circundavam Ludovic tentaram encontrar. Pelo menos para a psique, a história é experienciada como uma estranha combinação do "que aconteceu, do que não aconteceu, do que poderia ter acontecido, o que aconteceu com uma outra pessoa que não eu, o que não poderia ter acontecido e... uma afirmação que ninguém teria nem imaginado como representação do que realmente aconteceu" (Green, 2000, p.2-3). Na avaliação sonhadora de Green, é difícil separar, de uma vez por todas, a experiência de um evento de nossas esperanças e decepções. Essas escolhas libidinais são fascinantes e, às vezes, persecutórias em seu alcance. Elas sugerem uma outra visão sobre o que Melanie Klein entendeu por "uma certa dor", em que, ao mesmo tempo, se quer e não se quer a verdade. Nessa outra visão, o tempo convencional é deslocado; em seu lugar fica um curioso cálculo da questão que vimos chamando de existência enquanto tal. Nesse cálculo, novamente, o que Phillips chama de "uma atenção para a irregularidade (...) do que cada pessoa faz com o que recebe" é que parece provocar grande confusão no mundo. Os pais de Ludovic estão preocupados com a vida de Ludovic e como será seu futuro. Talvez eles desejem poupá-lo do ostracismo, da dor de viver a diferença em tantas direções. Talvez eles se sintam fracassados por não terem sido capazes de entender ou influenciar seu desejo, e talvez haja, ainda mesmo, um certo luto pela perda do que eles desejavam para seu filho. Mas não há esclarecimento para Ludovic; ele é tão teimoso quanto seu predecessor neste artigo, Fritz, e, dessa forma, resistente, não ao que Melanie Klein primeiramente chamou de os perigos e mistérios da sexualidade", mas à idéia mesma de escolher uma história antes que ela possa ser testada. Pareceme que Ludovic quer ser reconhecido ao mesmo tempo em que reconhece a si mesmo. E ele pode responder "Eu sei disso!" com tanta facilidade quanto seus predecessores neste artigo, Fritz e o Pequeno Hans.

Se a história é tão complicada, se ela é o nó feito entre a mistura de realidade e fantasia, há também, na psicanálise, algo bastante simples sobre isso. Por volta da época em que Melanie Klein estava completan- 
do a segunda parte do estudo de caso de Fritz, Sigmund Freud retornou ao seu "Pequeno Hans" para acrescentar um pós-escrito. Freud relatou o caso primeiramente em 1909. Em 1922, um "Pequeno Hans" de 19 anos se encontrou com Freud de novo, para dizer que leu o estudo de caso, mas mal pôde se reconhecer ali. Nem pôde lembrar qualquer coisa sobre sua inibição intelectual e pesquisas sexuais, disse ainda que, ao ler "Pequeno Hans", ele pensou se Freud estaria mesmo descrevendo a si mesmo com cinco anos de idade. O que realmente o adolescente Hans lembrava? Freud escreveu: "Portanto a análise não preservou os eventos da amnesia, mas foi tomada pela amnesia ela mesma." (Freud, 1909, pp.148-149) Exceto pelo fato de haver algo de que Hans se lembrava, e que agitou sua memória quando retornou a uma cidade que visitara uma vez quando criança e a qual associou a Freud.

Esse pós-escrito uniu dois pedaços da história: primeiro Freud usou essa ocasião para lembrar seus leitores que, quando "Pequeno Hans" foi publicado pela primeira vez, ele causou indignação social; muitos culparam a psicanálise por roubar a inocência das crianças e por falar sobre curiosidade e teorias sexuais das crianças. O público temeu o futuro e sentiu que a psicanálise, por escavar o passado, teria arruinado o que viria depois. Mas lá estava Hans, já crescido e bem.

O segundo pedaço da história referido por Freud é paradoxal. Nós temos história, porque temos esquecimento. E a forma como esquecemos é próxima ao que Freud chamou de "dormindo". O pós-escrito conclui: "Qualquer pessoa familiarizada com a psicanálise pode, de vez em quando, experimentar algo semelhante quando está dormindo. Ele será acordado por um sonho, e decidirá analisá-lo naquele exato momento; ele então dormirá de novo sentindo-se suficientemente satisfeito com os resultados de seus esforços; e, na próxima manhã, sonho e análise serão igualmente esquecidos" (Freud, 1909, p.149). Que esquisito, então, é encontrar uma criança-questão e não interrogar a criança, mas sim a história da questão. Talvez devêssemos rever a última descrição de Green da história da psique. Lá Green escreveu: "uma afirmação que alguém nunca tinha nem sonhado como representação do que realmente aconteceu." Aqui, podemos escrever "uma afirmação que sonhamos e então esquecemos." Ainda existe a questão da existência apresentada pelo arquivo e filme: o que acontece comigo sem que eu mesmo(a) perceba? 
Balint, M. (1992). The Basic Fault: Therapeutic Aspects of Regression. Evanston: Northwestern University Press.

Britzman, D. P. After Education: Anna Freud, Melanie Klein and Psychoanalytic Histories of Learning. State University of New York Press, Albany forthcoming.

Cohen, R. (2001). Ethics, Exegesis and Philosophy: Interpretation after Levinas. Cambridge: Cambridge University Press.

Ferenczi, S. (1933). Confusion of Tongues between Adults and the Child: The Language of Tenderness and Passion. Contemporary Psychoanalysis 24(2), abril, pp. 196-206, 1988.

Freud, S. (1953-1974) et col. The Standard Edition of the Complete Psychological Works of Sigmund Freud. (James Strachey, ed e trad.). (24 vols.). Londres: Hogarth Press and The Institute of Psychoanalysis.

--- (1975). The Theory of Child Analysis (1928[1927]). In The Writings of Anna Freud. (Vol. 1), 1922-1935. Nova lorque: International Universities Press.

. (1900). The Interpretation of Drea$m s, 2^{\text {mi }}$ part. SE 5 .

---. (1909). Analysis of a phobia in a five-year-old boy. SE X, 3-149.

(1912) .The Dynamics of Transference. SE XII, 97-108.

Green, A. (2000). Experience and Thinking. In André Green at the Squiggle Foundation, edited by Jan Abram. 1-15. Londres: Karnac Books.

(2000). Object(s) and subject. In André Green at the Squiggle Foundation, edited by Jan Abram, 17-38. Londres: Karnac Books.

Klein, M. (1930). The Importance of Symbol-Formation in the development of the ego. In Love, Guilt and Reparation and Other Works. pp. 219-32. 
-(1975). The Development of a Child (1921). In Love, Guilt and Reparation and Other works 1921-1945. pp. 1-53. Delacorte Press/Seymour Lawrence.

Phillips, A. (1998). The Beast in the Nursery: On Curiosity and Other Appetites. Nova Iorque: Pantheon Books.

Pitt, A. (2001). The Dreamwork of autobiography: Felman, Freud and Lacan. In Kathleen Weiler (ed. Feminist Engagements: Reading, Resisting, and Revisioning Male Theorists in Education and Cultural Studies), pp. 89-108. Nova Iorque: Routledge.

Pontalis, J.-B. (1981). Frontiers in Psychoanalysis: Between the Dream and Psychic Pain. (Catherine Cullen e Philip Cullen, trans.) Nova Iorque: International U.P.

Robertson, J. P. and Keon, N. (1999) The Question Child and Passing on Intergenerational Tales of Trauma: A Conversation with Elaine Kalman Naves. (Vol. 25,3) pp 29-49, Canadian Children's Literature, 1995.

\section{NOTAS}

1 Uma versão mais breve desse artigo foi originalmente apresentada na Reconstructing Early Education Conference, no Bank Street College, em Nova Iorque, no dia 3 de outubro de 2001. A pesquisa desse artigo foi financiada pelo Social Science and Humanities Research Council of Canada (Conselho de Pesquisas em Ciências Sociais e Humanidades do Canadá) sob o título "Conhecimento difícil no ensino e aprendizado: um questionamento psicanálitico", grant \# 41098-1028. Gostaria também de agradecer Jonathan Silin pelo convite para participar da mesa redonda.

2 Ao longo desse artigo estarei citando uma porção de psicanalistas que utilizam a imagem da criança-questão para "abrir as apostas" do diálogo psicanalítico, mas vale também notar o interessante uso que Robertson e Keon (1999) fizeram dessa imagem. Para os autores, a criança-questão é curiosa sobre sua história familiar, mais especificamente sobre sua sobrevivência ao holocausto. As perguntas da criança enervam o adulto: "Quando o pesadelo tocou os familiares e inscreveu sua fantasmagórica melodia de dor nos sobreviventes, questões sobre como responder às insistentes demandas dos jovens membros da família 'por saber' tornam-se ainda mais emaranhadas, complicadas e confusas." (p. 30)

3 A "Análise de uma fobia em um garoto de cinco anos" de Freud (1909) também é um apanhado suigeneris, já que Freud não viu o garoto realmente, exceto em uma única ocasião. O estudo de caso é a coleção das consultas e cartas que o pai de Hans trocou com Freud. Freud escreveu o texto em duas partes: uma descrição e então uma análise. O Pequeno Hans estava, naquele momento, a par das consultas de seu pai com Freud. A figura do "Professor Freud" é parte das conversas entre pai e filho. Hans usou essa figura como uma forma de sinalizar seus próprios pensamentos psicanalíticos. Por exemplo, o pai de Hans escreveu: "No dia primeiro de maio, Hans veio a mim na hora do almoço e disse: Sabe o quê? Vamos escrever alguma coisa para o Professor" (p. 97). Hans queria que seu pai registrasse uma fantasia.

4 Recupero esse interessante debate em meu próximo livro After Education: Anna Freud, Melanie Klein and Psychanalytic Histories, que será publicado pela The State University New York Press, Albany.

5 Klein parafraseia a maioria dessas questões. O fraseamento original pode ser encontrado nas páginas 8-9 de $O$ Desenvolvimento de uma Criança (na versão em inglês). 


\section{Artigo}

6 N.T. Recorte da tradução para o português feita por André Cardoso, In Klein, M. Amor, Culpa e Reparação e outros trabalhos. Rio de Janeiro, RJ: Imago, pp. 55-6.

7 N.T. No original "tense" que se refere ao tempo verbal.

8 N.T. Todas as traduções de citações feitas daqui em diante foram feitas por mim.

9 N.T. A expressão "ser nascido" é correta em inglês, e, embora não tenha equivalência em português, optei por mantê-la dessa forma para efeito de precisão da idéia de assujeitamento ao processo.

10 N.T. No original "The moving picture" abre para múltiplos significados que apontam tanto para a qualidade de movimento de um filme quanto para a qualidade comovente, tocante, emocionante do filme em questão.

Recebido em novembro/2001. 